\title{
Recurrent sick leave after COVID-19: investigating the first wave of the pandemic in a comprehensive Swedish registry-based study
}

\author{
Annie Palstam*, Emma Westerlind, Katharina S. Sunnerhagen and Hanna C. Persson
}

\begin{abstract}
Background: Sick-leave due to COVID-19 vary in length and might lead to re-current episodes. The aim was to investigate recurrent sick leave due to COVID-19 during the first wave.

Methods: This is a registry-based cohort study. The study comprises all people with sickness benefit due to COVID19 in Sweden in March 1-August 31, 2020. Data from the Swedish Social Insurance Agency, the Swedish National Board of Health and Welfare, and Statistics Sweden were merged.

Results: Within the follow-up period of 4 months, 11,955 people were subject to sickness benefit due to COVID-19, whereof 242 people (2.0\%) took recurrent sick leave due to COVID-19, and of those 136 (56.2\%) remained on sick leave at the end of follow-up. People with recurrent sick leave were older, more often women, and more likely to have been on sick leave prior to the COVID-19 pandemic.

Conclusion: A group of people presented with recurrent sick leave due to COVID-19. For half of them, the second sick leave lasted throughout the follow-up. People with recurrent sick leave differ in several aspects from those with shorter sick leave. To capture long-term sick-leave patterns due to COVID-19, a longer period of follow-up is needed.
\end{abstract}

Keywords: Sickness benefits, Return to work, Post-COVID, COVID-19, Registries

\section{Introduction}

All of society is affected by the COVID-19 pandemic. The long-term consequences are immeasurable for affected persons and their families, as well as for the economy, public health, health care, and the health insurance system. Furthermore, the symptoms of COVID-19 are diverse, including fever, cough, myalgia, and fatigue etc., and the severity, and functional impairments vary over

\footnotetext{
*Correspondence: annie.palstam@gu.se

Department of Clinical Neuroscience, Institute of Neuroscience and Physiology, Sahlgrenska Academy, University of Gothenburg, and Sahlgrenska University Hospital, Per Dubbsgatan 14, 3 tr, 41346 Gothenburg, Sweden
}

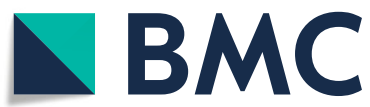

(c) The Author(s). 2021 Open Access This article is licensed under a Creative Commons Attribution 4.0 International License, which permits use, sharing, adaptation, distribution and reproduction in any medium or format, as long as you give appropriate credit to the original author(s) and the source, provide a link to the Creative Commons licence, and indicate if changes were made. The images or other third party material in this article are included in the article's Creative Commons licence, unless indicated otherwise in a credit line to the material. If material is not included in the article's Creative Commons licence and your intended use is not permitted by statutory regulation or exceeds the permitted use, you will need to obtain permission directly from the copyright holder. To view a copy of this licence, visit http://creativecommons.org/licenses/by/4.0/ The Creative Commons Public Domain Dedication waiver (http://creativecommons.org/publicdomain/zero/1.0/) applies to the data made available in this article, unless otherwise stated in a credit line to the data. prove the ability of people to return to ordinary routines, including work, are needed.

Sick leave is an indicator of well-being in the workingage population. In Sweden, sick-leave rates almost doubled during March and April 2020 compared with the previous year [7]. The financial compensation for sick leave is tax-funded and comprehensive in Sweden. However, the availability of paid sick leave varies globally [6]. National diagnosis-specific guidelines on sick leave are provided by the Swedish Social Insurance Agency and the National Board of Health and Welfare, and since June 2020 they have included COVID-19. Due to an 
insufficient knowledge base, the guidelines for COVID19 are vague, but they do acknowledge that an affected person's ability to work could decline not only in the acute phase but also in the aftermath [8].

Symptoms related to COVID-19, such as fatigue, dyspnoea, pain and depression, can be protracted and require intensive use of medical resources, regardless of the severity of the illness in the acute phase [9-13]. In our recent study on sick leave due to COVID-19 during the first wave in Sweden, 9\% were on sick leave at the end of the 4-month follow-up period [14]. However, recurrent sick leave was not investigated, and studies on recurrent sick leave due to COVID-19 has to our knowledge not been presented elsewhere.. The aim of this study was to investigate recurrent sick leave in people initially returning to work during the first wave of COVID-19, in terms of days, and differences compared to those with one shorter period of sick leave, in a national comprehensive cohort.

\section{Methods}

This is a registry-based study with data from the Swedish Social Insurance Agency, the Swedish National Board of Health and Welfare, and Statistics Sweden, based on the unique Swedish personal identification number. The personal identification numbers were used to pool data from different registries in the present study, and researchers had access only to a pseudonymised data set. A patient has been involved in the study as a partner in research, contributing to the research question and discussion of the results.

\section{Study population}

All people who were registered as receiving sickness benefits due to a COVID-19 diagnosis (International Statistical Classification of Diseases ICD [15] code U07) in Sweden from March 1 through August 31, 2020, were included in this study. Codes U (U00-U49) are used by WHO for provisional assignment of new diseases of uncertain etiology (https://icd.who.int/browse10/2019/en\#/ U07.1).

The follow-up period was 4 months (122 days) from the start of sick leave. Sickness benefits can be granted from the Swedish Social Insurance Agency to everyone who has been working in Sweden (both employed and self-employed) and also during parental leave, studies, and registered unemployment. If the person is employed, the employer pays sick pay for the first 2 weeks of absence due to sickness, and thereafter sickness benefits are provided. In the present study, sick leave is defined as receiving sickness benefits, regardless of amount.

\section{Sick leave}

The sick-leave period due to COVID-19 was counted as the number of days with sickness benefits and had to include at least one registration with a COVID-19 diagnosis. If sick pay was received in the first 2 weeks, these weeks were included in the sick leave period. If two sick leave periods were separated by a gap of $\leq 14$ days, they were merged into one period. Registered diagnoses related to COVID-19 that were merged into the sick leave period if they were registered within 14 days from the start or end of the COVID-19 sick leave are presented in Table 1.

Sick leave prior to COVID-19 was defined as being registered with sick leave for $\geq 28$ days or $\geq 6$ times between March 1, 2019, and the start of COVID-19 sick leave.

\section{Recurrent sick leave due to COVID-19}

Recurrent sick leave was defined as re-entry into sick leave due to COVID-19 (U07) or postviral fatigue syndrome (G93.3) with a gap of $>14$ days from the end of the first sick leave period, within the follow-up period.

The group with recurrent sick leave was compared with the sub-group in the total population that had short sick leave, which was defined as a period shorter than the median number of sick leave days for the total population (i.e., $<35$ days).

\section{Variables}

Data on employment status were retrieved from the Swedish Social Insurance Agency. The subgroups were employment (including parental leave, and combined employment and self-employment), self-employment, and unemployment (including studies).

Socioeconomic variables were collected from Statistics Sweden. Educational level was presented as primary school ( $\leq 9$ years), secondary school (10-12 years), short university education (13-14 years), and long university education ( $\geq 15$ years). Country of birth was categorised into Sweden, European countries except for Sweden, and countries outside of Europe. Marital status categories were married (including both marriage and registered partnership), single, and divorced and widow/widower. Income was reported in thousands of Swedish krona (SEK), 1 Euro = 10.18 SEK on March 25, 2021, and was the disposable income for each person.

Data on in-hospital care due to COVID-19 were retrieved from the Swedish National Board of Health and Welfare. In-hospital care due to COVID-19 was defined as at least 1 day of hospital stay with any of the U07 (COVID-19) diagnoses being registered. In cases where the COVID-19 diagnosis was a secondary diagnosis, the primary diagnosis is presented in Supplementary Table 1. The National Board of Health and Welfare furthermore 
Table 1 Diagnoses related to COVID-19

\begin{tabular}{|c|c|}
\hline Diagnoses related to COVID-19 & ICD codes \\
\hline Acute bronchitis & $J 20.9$ \\
\hline Acute lower respiratory infection & $\mathrm{J} 22, \mathrm{~J} 22.9$ \\
\hline $\begin{array}{l}\text { Acute laryngopharyngitis/acute upper respiratory } \\
\text { infection }\end{array}$ & J06, J06.8, J06.9 \\
\hline Acute laryngitis & J04.0 \\
\hline Asthma & $J 45, J 45.9$ \\
\hline Acute sinusitis & J01.9 \\
\hline Influenza due to unidentified influenza virus & $\mathrm{J11}, \mathrm{J11.8}$ \\
\hline Chronic tonsillitis & J35.0 \\
\hline Viral infection & $\begin{array}{l}\text { B34.2, B34.8, B34.9, } \\
\text { B34-P }\end{array}$ \\
\hline Sequelae of infectious and parasitic disease* & B94 \\
\hline Postviral fatigue syndrome* & G93.3 \\
\hline Fever & R50.9 \\
\hline Malaise and fatigue & R53, R53.9 \\
\hline Headache & R51.9 \\
\hline Haemoptysis & R04.2 \\
\hline Deep vein thrombosis* & Z86.7B \\
\hline $\begin{array}{l}\text { Family history of asthma and other chronic lower } \\
\text { respiratory disease }\end{array}$ & Z82.5 \\
\hline Nonrheumatic aortic (valve) insufficiency* & 135.1 \\
\hline Anxiety disorder* & $\begin{array}{l}\text { F41.0, F41.9, } \\
\text { F41.9P }\end{array}$ \\
\hline Reaction to stress* & $\begin{array}{l}\text { F43.0, F43.8, } \\
\text { F43.8A }\end{array}$ \\
\hline Depressive disorder* & F32.1, F32.9 \\
\hline
\end{tabular}

Abbreviation: ICD International Statistical Classification of Diseases * = related to COVID-19 only if it was registered after the COVID-19 diagnosis (U07) provided information about the date of death during the study period, when applicable.

\section{Statistical methods}

SPSS Statistics 25 (IBM) was used to manage and analyse the data. Fisher's exact test and the Mann-Whitney $\mathrm{U}$ test were used to analyse differences between groups in categorical and continuous variables, respectively. The significance level was set to $p<0.05$. To graphically present periods of sick leave in the group experiencing recurrent sick leave, a lasagne plot (Fig. 1) was created in SAS JMP 15. In cases of death during the study period, the person was registered as being on sick leave for the total time of the follow-up period.

\section{Results}

A total of 11,955 people were granted sickness benefits due to COVID-19 from March 1 through August 31, 2020, in Sweden. Characteristics of the study population are presented in Table 2. The median number of days on sick leave was 35 (IQR 26). For a sub-group of 1073 people $(9.0 \%)$, the sick leave continued throughout the 4 month follow-up period. Twenty-four people $(0.2 \%)$ died before the end of follow-up, all within $<10$ days from the end of the sick leave period due to COVID-19.

Two hundred and forty-two people (2.0\%) had recurrent sick leave. For the second sick leave period, 133 (55.0\%) were registered as U07.1 (COVID-19, virus identified), 76 (31.4\%) as U07.2 (COVID-19, virus unidentified), and 33 (13.6\%) as G93.3 (postviral fatigue syndrome). In addition, three people had a third sickleave period due to COVID-19 within the follow-up period.

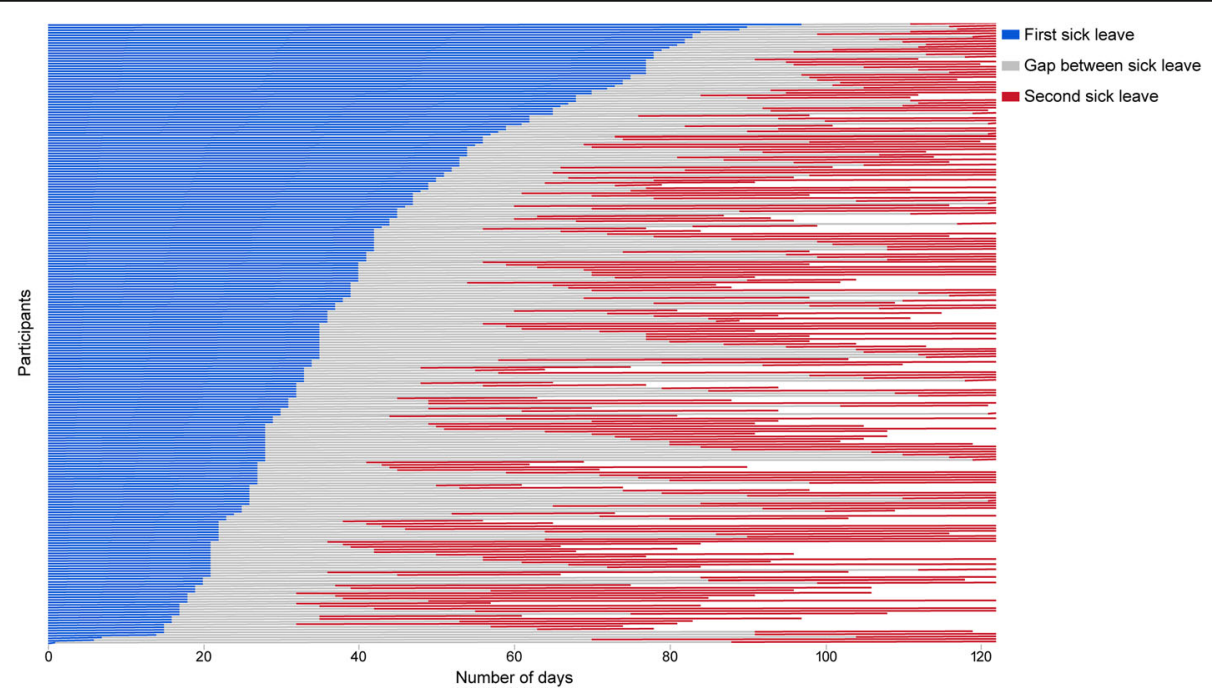

Fig. 1 Recurrent sick leave in 242 people during the four month follow-up period. The white areas indicate no longer being on sick leave 
Table $\mathbf{2}$ Characteristics of the study population

\begin{tabular}{|c|c|}
\hline Participants, n (\%) & $11,955(100.0)$ \\
\hline \multicolumn{2}{|l|}{ Sex, n (\%) } \\
\hline Men & $4826(40.4)$ \\
\hline Women & $7129(59.6)$ \\
\hline Age, mean (SD) & $48.0(11.3)$ \\
\hline \multicolumn{2}{|l|}{ Country of birth, $\mathrm{n}(\%)^{\mathrm{a}}$} \\
\hline Sweden & $7545(63.1)$ \\
\hline European countries except for Sweden & $1481(12.4)$ \\
\hline Countries outside of Europe & $2929(24.5)$ \\
\hline \multicolumn{2}{|l|}{ Educational level, $\mathrm{n}(\%)^{\mathrm{b}}$} \\
\hline Primary school ( $\leq 9$ years) & $1237(10.4)$ \\
\hline Secondary school (10-12 years) & 5889 (49.6) \\
\hline Short university education (13-14 years) & $1743(14.7)$ \\
\hline Long university education ( $\geq 15$ years) & $3995(25.2)$ \\
\hline Income, 1000 SEK median $(\mathrm{IQR})^{\mathrm{c}}$ & $288(117)$ \\
\hline \multicolumn{2}{|l|}{ Marital status, n (\%) ${ }^{d}$} \\
\hline Married & $5812(48.8)$ \\
\hline Single & 3859 (32.4) \\
\hline Divorced and widow/widower & $2246(18.8)$ \\
\hline Sick leave prior to COVID-19, n (\%) & $1932(16.2)$ \\
\hline \multicolumn{2}{|l|}{ Employment status, n (\%) ${ }^{\mathrm{e}}$} \\
\hline Employment & $11,460(95.9)$ \\
\hline Self-employment & $288(2.4)$ \\
\hline Unemployment & $204(1.7)$ \\
\hline In-hospital care due to COVID-19, n (\%) & $2960(24.8)$ \\
\hline
\end{tabular}

Abbreviation: $S D$ standard deviation, IQR interquartile range $\mathrm{a}=9$ missing, $\mathrm{b}=91$ missing, $\mathrm{c}=2$ missing, $\mathrm{d}=38$ missing, $\mathrm{e}=3$ missing

The median number of days of the first sick leave period for the group with recurrent sick leave was similar to that of the total population, which was 35 (IQR 24) (Fig. 1). The median number of days between the initial and the recurrent sick-leave periods due to COVID-19 was 33.5 (IQR 31). The median number of days of the second sick-leave period was 26 (IQR 26) at the end of follow-up. A total of 136 (56.2\%) people with recurrent sick leave were still on sick leave at the end of the 4-month follow-up.

People with recurrent COVID-19 sick leave were significantly older and more often women than people with one shorter period of sick leave (<35 days) (Table 3 ). Furthermore, the group with recurrent sick leave was more likely to have been on sick leave prior to COVID19 , and there were significant differences in country of birth, educational level, employment status, marital status, and income. There was no significant difference in in-hospital care due to COVID-19 between the two groups (Table 3$)$.

\section{Discussion}

In this national registry-based study, comprising all people on sick leave during the first wave of COVID-19 in Sweden, 2\% had recurrent sick leave during the 4month follow-up period. The second period of sick leave varied in length and point in time within the follow-up period, and over half of the population with recurrent sick leave was still on sick leave at the end of follow-up, indicating a need for a longer period of follow-up to explore long-term sick leave patterns. The group of people with recurrent sick leave due to COVID-19 differed in several aspects from the group of people with one shorter sick leave.

There were 136 people with recurrent sick leave who were still on sick leave at the end of the 4-month followup period. Increasing sick-leave rates have been observed during influenza epidemics, a recent example being the H1N1 epidemic [16]. However, reports of previous pandemics of viral infections resulting in long-term sick leave or recurrent sick leave are lacking. In our previous study [14] on the same cohort $(n=11,955)$, we showed that $9 \%(n=1073)$ of the population were on their initial sick leave for the entire follow-up period. Taking into account recurrent sick leave, the number of people with longer periods of sick leave due to post COVID-19 symptoms is probably higher than previously reported. It can also be speculated that a longer follow-up period could reveal more people registered with recurrent sick leave at a later phase. It seems that long-term follow-up is needed to attain the full picture of the effect COVID19 has had on public health.

People with recurrent sick leave due to COVID-19 were more likely to be older, female, and to have had prior sick leave during the prior year than those who had one shorter period of sick leave. However, the groups were similar regarding in-hospital care due to COVID-19. The patterns of sick leave may depend on several circumstances. The Swedish national guidelines for sick leave due to COVID-19 were first published in June 2020 and are still under development [17], and this could influence the country's sick leave patterns. Furthermore, the government regulations on quarantine due to COVID-19 and available testing have varied since the pandemic began. Recurrent periods of sick leave could be due to persistent symptoms or onset of new symptoms post COVID-19 [18]. Recurrent sick leave could also be due to return to work with reduced work capacity, which has been reported as a risk for future sick leave in other diseases but not yet in COVID-19 [19]. Occupational characteristics, such as a low level of adjustment latitude, could also hinder return to work [20].

This study included only people with sickness benefits. In Sweden, this generally includes people with a sick- 
Table 3 Characteristics of the work instability group compared with the group of people with short sick leave $(<35$ days $)$ due to COVID-19

\begin{tabular}{|c|c|c|c|}
\hline & Group with recurrent sick leave & Group with one shorter period of sick leave & $p$-value \\
\hline Participants, n & 242 & 5343 & \\
\hline Sex, n (\%) & & & 0.011 \\
\hline Men & $77(31.8)$ & $2143(40.1)$ & \\
\hline Women & $165(68.2)$ & $3200(59.9)$ & \\
\hline Age in years, mean (SD) & $48.7(10.4)$ & $46.9(11.4)$ & 0.023 \\
\hline Country of birth, n (\%) & & & 0.015 \\
\hline Sweden & $177(73.1)$ & $3418(64.0)$ & \\
\hline European countries except for Sweden & $23(9.5)$ & $650(12.2)$ & \\
\hline Countries outside of Europe & $42(17.4)$ & $1270(23.8)$ & \\
\hline Educational level, n (\%) & & & 0.001 \\
\hline Primary school ( $\leq 9$ years) & $25(10.3)$ & 507 (9.6) & \\
\hline Secondary school (10-12 years) & $99(40.9)$ & $2672(50.5)$ & \\
\hline Short university education (13-14 years) & $28(11.6)$ & $772(14.6)$ & \\
\hline Long university education ( $\geq 15$ years) & $90(37.2)$ & $1342(25.4)$ & \\
\hline Income: 1000 SEK median (IQR) & $276(103)$ & $289(117)$ & 0.042 \\
\hline Marital status, n (\%) & & & 0.006 \\
\hline Married & $95(39.3)$ & $2576(48.3)$ & \\
\hline Single & $88(36.4)$ & $1831(34.3)$ & \\
\hline Divorced and widow/widower & $59(24.4)$ & $929(17.4)$ & \\
\hline Sick leave prior to COVID-19, n (\%) & $55(22.7)$ & $735(13.8)$ & $<0.001$ \\
\hline Employment status, n (\%) & & & 0.030 \\
\hline Employment & $225(93.4)$ & $5160(96.6)$ & \\
\hline Self-employment & $9(3.7)$ & $105(2.0)$ & \\
\hline Unemployment & $7(2.9)$ & $77(1.4)$ & \\
\hline In-hospital care due to COVID-19, n (\%) & $46(19.0)$ & $966(18.1)$ & 0.733 \\
\hline
\end{tabular}

leave period of more than 2 weeks. Furthermore, the cohort included few deaths compared with national agematched data [21], which may be explained by the risk of people dying prior to being registered with sickness benefits for COVID-19.

An important methodological consideration is the definition of COVID-19 sick-leave periods. Approximately one-third of the people were classified as "COVID-19, virus undetected", indicating uncertainty in the data. Data were collected during the first wave in Sweden, when PCR testing was limited. In the present study, the "COVID-19, virus undetected" diagnosis was classified as a COVID-19 infection, to capture the picture of sick leave due to COVID-19. Sick leave due to related diagnoses were merged into the period of COVID-19 sick leave if the gap between sick leaves was shorter than 14 days. The 14-day cutoff was based on clinical experience and reasoning, to limit the risk of missing substantial sick leave data due to registration difficulties (first-wave data, early in the pandemic). However, there may be a risk that a small number of the sick-leave periods were due not only to COVID-19. The cut-off also affects the results, in that the shortest time possible between the initial and the recurrent sick leave was 14 days.

It is clear that a period of 4 months is too short to give a full and comprehensive view of the sick-leave patterns over time in this complex and heterogeneous disease, and longer periods of follow-up are needed in order to capture data on sustainable return to work in this population. Furthermore, sick leave and the ability to work are closely related to an individual's occupation and type of work, which are unknown characteristics in this cohort.

To our knowledge this is the first national registrybased cohort study describing recurrent sick leave due to COVID-19. Information on sick-leave patterns from the present study could be useful for guidelines and recommendations regarding sick leave and rehabilitation needs due to COVID-19. 


\section{Conclusion}

In this national cohort with people receiving sickness benefits in the first wave of the COVID-19 pandemic in Sweden, a group of people presented with recurrent sick leave due to COVID-19. The group with recurrent sick leave differs in several aspects from the group with shorter sick leave. For half of them, the second sick leave lasted throughout the follow-up period. People with sick leave prior to COVID-19 seem to be vulnerable to recurrent sick leave, and may need early attention and support in vocational rehabilitation. A longer follow-up period is needed to capture long-term sick-leave patterns due to COVID-19.

\section{Abbreviations}

SD: Standard deviations; IQR: Interquartile range

\section{Supplementary Information}

The online version contains supplementary material available at https://doi. org/10.1186/s12889-021-11918-y.

Additional file 1: Table S1. Primary diagnosis for inpatient care if not COVID-19.

\section{Acknowledgments}

The authors would like to acknowledge the registry holder, the Swedish Social Insurance Agency, the Swedish National Board of Health and Welfare, and Statistics Sweden for providing data. We would also like to thank our patient partner, Helena Strömberg, for her knowledgeable contribution to the research question and discussion of the results, and Tamar Abzandadze for her contribution to the figure illustrations.

\section{Authors' contributions}

EW, AP, HCP, and KSS were involved in the conceptualisation and funding acquisition of the study. EW, AP, and HCP were involved in data collection, and EW did the data handling, formal analysis, and were responsible for the Figs. EW, AP, HCP, and KSS were involved in data interpretation and manuscript writing. The author(s) read and approved the final manuscript.

\section{Funding}

This study was founded by grants from the Swedish state under an agreement between the Swedish government and the county councils (ALF 73750, ALF 71980), AFA Insurance AFA 200324, Forte/Formas (2020-02775), and Vastragotaland regional research funding (VGFOUREG-940508). Open Access funding provided by University of Gothenburg.

\section{Availability of data and materials}

The datasets used and/or analysed during the current study are available from the corresponding author on reasonable request. They are not publicly available, in accordance with the Ethics Review Authority. The study protocol and statistical analysis plan are available at https://www.researchweb.org/is/ vgr/project/274476.

\section{Declarations}

\section{Ethical approval and consent to participate}

The study was approved by the Swedish Ethical Review Authority, Dnr: 2020-03046 and 2020-03922. Permissions to access the raw data from the Swedish Social Insurance Agency, the Swedish National Board of Health and Welfare, and Statistics Sweden were granted by each authority, respectively, upon ethical approval and prior to data retrieval. The data have been handled in pseudonymised form, with the code key kept by the registry holders. All methods/analyses were performed in accordance with the Declarations of Helsinki.

\section{Consent for publication}

Not applicable.

\section{Competing interests}

The authors declare that they have no competing interests.

Received: 28 May 2021 Accepted: 5 October 2021

Published online: 21 October 2021

References

1. Borg K, Stam H. Editorial: Covid-19 and Physical and Rehabilitation Medicine. J Rehabil Med. 2020;52(4):jrm00045.

2. Stam HJ, Stucki G, Bickenbach J. Covid-19 and Post Intensive Care Syndrome: A Call for Action. J Rehabil Med. 2020;52(4):jrm00044.

3. Brugliera L, Spina A, Castellazzi P, Cimino P, Tettamanti A, Houdayer E, et al. Rehabilitation of COVID-19 patients. J Rehabil Med. 2020;52(4):jrm00046.

4. Gutenbrunner C, Stokes EK, Dreinhofer K, Monsbakken J, Clarke S, Cote P. et al. Why Rehabilitation must have priority during and after the COVID-19pandemic: A position statement of the Global Rehabilitation Alliance. J Rehabil Med. 2020;52(7):jrm00081

5. Helms J, Kremer S, Merdji H, Clere-Jehl R, Schenck M, Kummerlen C, et al. Neurologic features in severe SARS-CoV-2 infection. N Engl J Med. 2020; 382(23):2268-70. https://doi.org/10.1056/NEJMc2008597.

6. Khan F, Amatya B. Medical Rehabilitation in Pandemics: Towards a New Perspective. J Rehabil Med. 2020;52(4):jrm00043.

7. Försäkringskassan (Swedish Social Insurance Agency). Rapport - Effekter som covid-19 har på sjukförsäkringen. 2021. 2021-01-19. Report No.: FK 2020/000065

8. Socialstyrelsen (National board of health and welfare). Covid-19 (inkl de patienter som fått intensivvård med respiratorbehandling) [Försäkringsmedicinsk beslut]. 2021 [updated 2021-02-11; cited 2021 2021-03-05]. Available from: https://roi.socialstyrelsen.se/fmb/COVID-19inkl-de-patienter-som-fatt-intensivvard-med-respiratorbehandling/702.

9. Carvalho-Schneider C, Laurent E, Lemaignen A, Beaufils E, Bourbao-Tournois C, Laribi S, et al. Follow-up of adults with noncritical COVID-19 two months after symptom onset. Clin Microbiol Infect. 2021;27(2):258-63. https://doi. org/10.1016/j.cmi.2020.09.052.

10. Davis HE, Assaf GS, McCorkell L, Wei H, Low RJ, Re'em Y, et al. Characterizing Long COVID in an International Cohort: 7 Months of Symptoms and Their Impact. medRxiv. 2020:2020.12.24.20248802.

11. Michelen M, Manoharan L, Elkheir N, Cheng V, Dagens D, Hastie C, et al Characterising long-term covid-19: a rapid living systematic review. medRxiv. 2020:2020.12.08.20246025.

12. Sudre CH, Murray B, Varsavsky T, Graham MS, Penfold RS, Bowyer RC, et al. Attributes and predictors of Long-COVID: analysis of COVID cases and their symptoms collected by the Covid Symptoms Study App. medRxiv. 2020: 2020.10.19.20214494

13. Huang C, Huang L, Wang Y, Li X, Ren L, Gu X, et al. 6-month consequences of COVID-19 in patients discharged from hospital: a cohort study. Lancet. 2021;397(10270):220-32. https://doi.org/10.1016/S0140-6736(20)32656-8.

14. Westerlind E, Palstam A, Sunnerhagen KS, Persson HC. Patterns and predictors of sick leave after Covid-19 and long Covid in a national Swedish cohort. BMC Public Health. 2021; In press.

15. World Health O. International statistical classification of diseases and related health problems. 10th revision. ed: Geneva; 1992

16. de Blasio BF, Xue Y, Iversen B, Gran JM. Estimating influenza-related sick leave in Norway: was work absenteeism higher during the 2009 A(H1N1) pandemic compared to seasonal epidemics? Euro Surveill. 2012;17(33): 20246. https://doi.org/10.2807/ese.17.33.20246-en.

17. Försäkringsmedicinskt beslutsstöd. 2020

18. Havervall S, Rosell A, Phillipson M, Mangsbo SM, Nilsson P, Hober S, et al. Symptoms and functional impairment assessed 8 months after mild COVID19 among health care workers. JAMA. 2021;325(19):2015-6. https://doi.org/1 $0.1001 /$ jama.2021.5612

19. Janssens H, Clays E, De Clerca B, De Bacquer D, Braeckman L. The relation between presenteeism and different types of future sickness absence. J Occup Health. 2013;55(3):132-41. https://doi.org/10.1539/ joh.12-0164-OA. 
20. Hultin $\mathrm{H}$, Hallqvist J, Alexanderson $\mathrm{K}$, Johansson G, Lindholm C, Lundberg I, et al. Low level of adjustment latitude--a risk factor for sickness absence. Eur J Pub Health. 2010;20(6):682-8. https://doi.org/10.1093/eurpub/ckp240.

21. Socialstyrelsen (National board of health and welfare). 2021. Available from: https://www.socialstyrelsen.se/statistik-och-data/statistik/statistik-om-covid-1 9/statistik-over-antal-avlidna-i-covid-19/.

\section{Publisher's Note}

Springer Nature remains neutral with regard to jurisdictional claims in published maps and institutional affiliations.

- fast, convenient online submission

- thorough peer review by experienced researchers in your field

- rapid publication on acceptance

- support for research data, including large and complex data types

- gold Open Access which fosters wider collaboration and increased citations

- maximum visibility for your research: over $100 \mathrm{M}$ website views per year

At $\mathrm{BMC}$, research is always in progress. 